\title{
Role of estrogen in lung cancer based on the estrogen receptor-epithelial mesenchymal transduction signaling pathways
}

This article was published in the following Dove Press journal:

OncoTargets and Therapy

9 October 2015

Number of times this article has been viewed

Xiao-zhen Zhao, ${ }^{1, *}$ Yu Liu, ${ }^{1, *}$ Li-juan Zhou, ${ }^{1} *$ Zhong-qi Wang,' Zhong-hua Wu, ${ }^{2}$ Xiao-yuan Yang ${ }^{3}$

'Department of Tumor, Longhua Hospital, ${ }^{2}$ Center of Science and Technology, Shanghai University of Traditional Chinese Medicine, Shanghai, People's Republic of China; ${ }^{3}$ Department of Molecular Pharmacology and Physiology, Morsani College of Medicine, University of South Florida, Tampa, FL, USA

*These authors contributed equally to this work

\section{Video abstract}

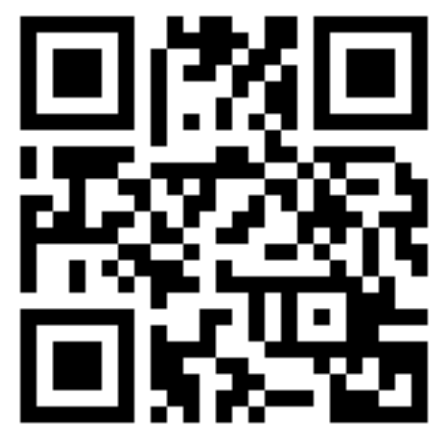

Point your SmartPhone at the code above. If you have a OR code reader the video abstract will appear. Or use: http://youtu.be/ShaWSismyqk

Correspondence: Xiao-zhen Zhao Department of Tumor, Longhua Hospital, Shanghai University of Traditional Chinese Medicine, 725 Wanping Road, Xuhui District, Shanghai 200032, People's Republic of China Tel +86 I37 64640054 Email zhxzhtiger200।@126.com
Background/aim: Estrogen is reported to promote the occurrence and development of several human cancers. Increasing evidence shows that most human lung tumors exert estrogen receptor expression. In the present study, we investigated the underlying mechanism of estrogen effect in lung cancer through estrogen receptor-epithelial-mesechymal-transition signaling pathways for the first time.

Materials and methods: A total of 36 inbred C57BL/6 mice (18 male and 18 female) were injected subcutaneously with human lung adenocarcinoma cell line, Lewis. After the lung tumor model was established, mice with lung adenocarcinoma were randomly divided into three groups for each sex $(n=6)$, such as vehicle group, estrogen group, and estrogen plus tamoxifen group. The six groups of mice were sacrificed after 21 days of drug treatment. Tumor tissue was stripped and weighed, and tumor inhibition rate was calculated based on average tumor weight. Protein and messenger RNA (mRNA) expressions of estrogen receptor $\alpha(E R \alpha)$, estrogen receptor $\beta(E R \beta)$, phosphatidylinositol 3'-kinase (PI3K), AKT, E-cadherin, and vimentin were detected in both tumor tissue and lung tissue by using immunohistochemistry and real-time reverse transcription-polymerase chain reaction.

Results: 1) For male mice: in the estrogen group, estrogen treatment significantly increased ER $\alpha$ protein and mRNA expressions in tumor tissue and protein expression of PI3K, AKT, and vimentin in both tumor tissue and lung tissue compared with the vehicle-treated group. Besides, mRNA expression of E-cadherin was significantly reduced in estrogen-treated tumor tissues than that in vehicle-treated tissues. In the estrogen plus tamoxifen group, protein and mRNA expressions of $\mathrm{ER} \alpha$ and AKT were dramatically reduced by tamoxifen treatment in tumor tissue compared with the estrogen group; mRNA expression of E-cadherin was increased in tumor tissue; protein expression of vimentin and PI3K were downregulated in tumor tissue; protein expression of E-cadherin increased in lung tissue; protein expression of $\mathrm{ER} \alpha$ and PI3K were downregulated in lung tissue compared with the estrogen group. 2) For female mice: in the estrogen group, estrogen treatment significantly increased mRNA expression of ER $\beta$ and PI3K, and protein expression of ER $\beta$, PI3K, $\mathrm{AKT}$, and vimentin in both tumor tissue and lung tissue compared with the vehicle-treated group. mRNA expression of E-cadherin was downregulated in tumor tissue, and mRNA expression of AKT was increased in lung tissues compared with the vehicle-treated group. In the estrogen plus tamoxifen group, tamoxifen treatment dramatically reduced protein expression of ER $\alpha, \mathrm{ER} \beta, \mathrm{AKT}$, and vimentin but significantly increased protein expression of E-cadherin in tumor tissues and lung tissue compared with the estrogen group. mRNA expression of ER $\beta, P I 3 K$, and AKT was dramatically reduced by tamoxifen treatment in lung tissues compared with the estrogen group.

Conclusion: Estrogen promoted lung adenocarcinoma cell metastasis by inducing lung epithelial mesenchymal cells and reducing intercellular adhesion force through PI3K/AKT signaling pathway.

Keywords: Lewis lung carcinoma, estrogen, estrogen receptor, epithelial-mesenchymal transition 


\section{Introduction}

The incidence and mortality of lung cancers are increasing all over the world. The therapeutic effects of surgery, radiotherapy, chemotherapy, and targeted therapy for lung cancer are limited in clinical research. Therefore, novel therapeutic strategies for lung cancer patients are needed.

Recently, it has been suggested that estrogen plays an important role in the occurrence, development, and metastasis of lung cancers. Niikawa et al detected 59 cases of non-small-cell lung cancer (NSCLC) patients and found that estrogen levels of tumor tissues were 2.2 times higher than that of adjacent normal lung tissues in 43 cases. ${ }^{1}$ Accumulating evidence has showed that estrogen receptors (ERs) are expressed in NSCLC. In 1982, Chaudhuri, an American pathologist, first reported the expression of ER in lung cancer tissues; Chaudhuri et al discovered that $57 \%$ positive expression of ER was found in adenocarcinoma tissues, while no expression of ER was found in squamous carcinoma and small cell carcinoma. ${ }^{2}$ Estrogen binds to ER, interacts with the P85 $\alpha$ (the regulatory subunit of phosphatidylinositol 3'-kinase [PI3K]) and P110 (the catalytic subunit of PI3K), and triggers the activation of downstream kinase AKT. AKT activation modulates its downstream protein function through phosphorylation and subsequently regulates cell proliferation, differentiation, apoptosis, and migration..$^{3-5}$

Epithelial-mesechymal-transition (EMT) is characterized as a process that epithelial cells turn into interstitial cells under certain physiological or pathological conditions. Correlational studies have demonstrated that the occurrence of EMT is the key step to induce the invasion and metastasis of lung cancers. ${ }^{6-8}$ The main features of EMT include decreased epithelial cell markers (E-cadherin, CK19 protein) and increased mesenchymal cell markers (N-cadherin, vimentin). These phenotypic changes lead to alerted biological behavior and reduced adhesion capacity of tumor cells, eventually causing tumor cell invasion. Grille et al transfected constant activated AKT into human squamous cancer cell line SCC15 cells and revealed that SCC15 cells lost the morphological features of squamous epithelial cells after the transfection. ${ }^{9}$ This finding indicates that AKT directly affects epithelial cell morphological characteristics, motility, and invasion abilities.

Thus, we hypothesized that estrogen may promote lung cancer EMT through PI3K/AKT signaling pathway, resulting in the invasion and metastasis of lung cancer.

\section{Materials and methods Cell cultures and transduction}

The human lung adenocarcinoma cell line, Lewis, was provided by Dr Wenlong Ren (Pharmaceutical Engineering Research
Center, Shanghai, People's Republic of China). The cells were cultured in the Roswell Park Memorial Institute 1640 medium (Thermo Fisher Scientific, Waltham, MA, USA) supplemented with $10 \%$ fetal bovine serum (Thermo Fisher Scientific). Cells were grown at $37^{\circ} \mathrm{C}$ in a humidified incubator with $5 \% \mathrm{CO}_{2}$. Ethical permission for the human lung adenocarcinoma cell line was not necessary, as the cell line was purchased from the Chinese Academy of Sciences, Shanghai.

\section{Subcutaneous mouse models of lung cancer}

All experimental procedures were conducted in conformity with institutional guidelines for the care and use of laboratory animals, and protocols were approved by the Institutional Animal Care and Use Committee in Shanghai University of Traditional Chinese Medicine.

A total of 36 inbred C57BL/6 mice (6-8 weeks old, half male and half female) were purchased from Slack Laboratory Animal Co., Ltd. (Shanghai, People's Republic of China). The mice were maintained in laminar flow cabinets under specific pathogen-free conditions with controlled temperature $\left(21^{\circ} \mathrm{C}-\right.$ $23^{\circ} \mathrm{C}$ ) and $12 / 12$-hour light/dark cycles in the experimental animal center of Traditional Chinese Medicine of Shanghai University. The $0.2 \mathrm{~mL}\left(1 \times 10^{7}\right.$ cells $\left./ \mathrm{mL}\right)$ Lewis cell pellets were subcutaneously injected into right axilla of mice. Mice of each sex were randomly divided into three experimental groups $(n=6)$ such as the vehicle group, the estrogen group, and the estrogen plus tamoxifen group. Mice in the vehicle group were administrated with estrogen or tamoxifen the day after tumor cell injection and were intragastrically lavaged with $0.4 \mathrm{~mL}$ of $0.9 \%$ sodium chloride solution (two times/day). Mice in the estrogen group were gavaged with $0.4 \mathrm{~mL}$ of diluted estradiol valerate tablets (1:80; Bayer HealthCare Co. Ltd., Guangzhou, People's Republic of China) once per day and $0.4 \mathrm{~mL}$ of $0.9 \%$ sodium chloride solution (one time/day). Mice in the estrogen plus tamoxifen group were gavaged with $0.4 \mathrm{~mL}$ of diluted estradiol valerate tablets (one time/day) and $0.4 \mathrm{~mL}$ of diluted tamoxifen (1:80; Fudan Fuhua Pharmaceutical Co. Ltd., Shanghai, People's Republic of China) once per day.

Animal welfare was considered with appropriate measures to monitor and alleviate suffering implementation. All mice were fed standard mouse chow. Body weight and tumor growth were measured every 4 days with electronic scale and vernier caliper after tumor cell injection. A total of 36 mice were euthanized by an overdose of $\mathrm{CO}_{2}$ followed by cervical dislocation and underwent necropsy 21 days after tumor cell injection, when tumor size reached $10 \mathrm{~mm}$. Tumor and mice lung tissues were removed for further evaluation. 


\section{Hematoxylin and eosin staining}

Tumor and lung tissues from each mouse were fixed in 10\% formalin and embedded in paraffin for sectioning. Then, hematoxylin and eosin (H\&E) staining, paraffin-embedded tumor, and lung tissues were sectioned $(5 \mu \mathrm{m})$. The wax slices were dewaxed by dimethyl benzene and then dehydrated step by step with ethanol. The slices were stained for 5 minutes with hematoxylin (Gene Technology Shanghai Co., Ltd., Shanghai, People's Republic of China) and then placed in eosin solution (Gene Technology Shanghai Co., Ltd.) for 2 minutes. Dehydrate and seal the slices conventionally.

\section{Real-time PCR method}

Total RNA of tumor tissue and lung tissue were extracted by Trizol (Life Technologies, Carlsbad, CA, USA). The concentration of RNA was measured by a spectrophotometer (752; The Third Analytical Instrument Factory, Shanghai, People's Republic of China). Two micrograms of RNA was used for reverse transcription. Estrogen receptor $\alpha(E R \alpha)$, estrogen receptor $\beta$ (ER $\beta)$, PI3K, AKT, E-cadherin, and vimentin messenger RNA (mRNA) were amplified by ABI Stepone System (7500 fast; Applied Biosystems, USA). The amplification was carried out in a total volume of $20 \mu \mathrm{L}$ containing $10 \mu \mathrm{L}$ SYBR Green (TAKARA, Japan), $5.6 \mu \mathrm{L}$ sterile water, $0.4 \mu \mathrm{L}$ RoxDye, $2 \mu \mathrm{L}$ cDNAL, and $2 \mu \mathrm{L}$ primer. Cycling conditions were as follows: initial enzyme activation at $95^{\circ} \mathrm{C}$ for 30 seconds, followed by 40 cycles of denature at $95^{\circ} \mathrm{C}$ for 3 seconds, anneal and extend at $60^{\circ} \mathrm{C}$ for 30 seconds. The primers for ER $\alpha$ were $5^{\prime}$-GGGGAGCATCGAGTACA GC-3' (forward) and 5'-AGACGCACACC CTC CTTGA-3' (reverse); the primers for ER $\beta$ were 5'-CTGTGATGAACTACAGTGTT CCC-3' (forward) and 5'-CACATTTGG GCTTGCAGTCTG-3' (reverse); the primers for PI3K were 5'-CTACCCTGAGCTAC TACCTCCC-3' (forward) and 5'-CGCCAGCAGTG AATAAGGAGTA A-3' (reverse); the primers for AKT were 5'-ATGAACGACGTAGCC ATTGTG-3' (forward) and 5'-TTGTAGCCAATAAAGGTGCCAT-3' (reverse); the primers for E-cadherin gene were 5'-CAGTTC CGAGGTCTACACCTT-3' (forward) and 5'-TGAATCG GGAGTCTTCC GAAAA-3' (reverse); the primers for vimentin were 5'-C GTCCACACGCACCTA CA G-3' (forward) and 5'-GGGGG ATGAGGAATAGAG GCT-3' (reverse); and the primers for mGAPDH were 5'-AGGTCGGTGTGAACGGATTTG-3' (forward) and 5'-TGTAGACCATGTAGTTGAGGTCA-3' (reverse).

\section{Immunohistochemistry}

The sections were heated in a microwave oven in citrate buffer ( $\mathrm{pH}=6.0$ ) for 20 minutes at $95^{\circ} \mathrm{C}$ and cooled at room temperature. The sections were then washed with phosphate buffered saline (PBS) for three times (3 minutes/ time). Endogenous peroxidase activity was blocked in 3\% $\mathrm{H}_{2} \mathrm{O}_{2}$ for 20 minutes at room temperature. After washing with PBS for three times (3 minutes/time), sections were incubated with normal goat serum for 30 minutes at room temperature. The sections were then incubated overnight at $4^{\circ} \mathrm{C}$ with specificity primary antibody (anti-ER $\alpha$ [ab37438], Abcam, UK; anti-ER $\beta$ [ab3576], Abcam; PI3 kinase p110 $\alpha$ [C73F8], Cell Signaling, USA; AKT [C73H10], Cell Signaling; E-cadherin [24E10], Cell Signaling; vimentin [D21H3], Cell Signaling) $37^{\circ} \mathrm{C}$ rewarming for 45 minutes. The sections were washed three times with PBS (3 minutes/ time), then incubated with GTVision (Gene Technology Shanghai Co., Ltd., Shanghai, People's Republic of China) for 30 minutes at $37^{\circ} \mathrm{C}$. The sections were then washed three times with PBS and visualized with diaminnobenzidinetetra-hydrochloride (DAB kit; Shanghai Secco Chemical Technology Co., Ltd., People's Republic of China). Finally, the sections were counterstained with hematoxylin and dehydrated.

\section{Image analysis}

Immunohistochemistry images were analyzed by using Image-Pro-Plus 6 image analysis system. The immunohistochemical positive area, positive rate, and cumulative value of optical density were measured under high magnification for 400×. We analyzed five images from each group of each indicator. Unit conversion: total area $=4,915,200$ pixels.

\section{Statistical analysis}

All group data were analyzed performed using SPSS statistical software 18.0 (SPSS Inc., Chicago, IL, USA). Difference/ correlations between two groups were assessed by one-way analysis of variance. If the variance does not show irregularity, data were calibrated with the Games-Howell test. Differences at $P<0.05$ were considered to be statistically significant.

\section{Results Mice body weight}

After tumor cell injection, mice were weighted every 4 days. In male mice, the average mice weight in the estrogen plus tamoxifen group was significantly higher than that in the estrogen group on the 16th day and 20th day (Figure 1A). In female mice, average body weight in the estrogen group was 

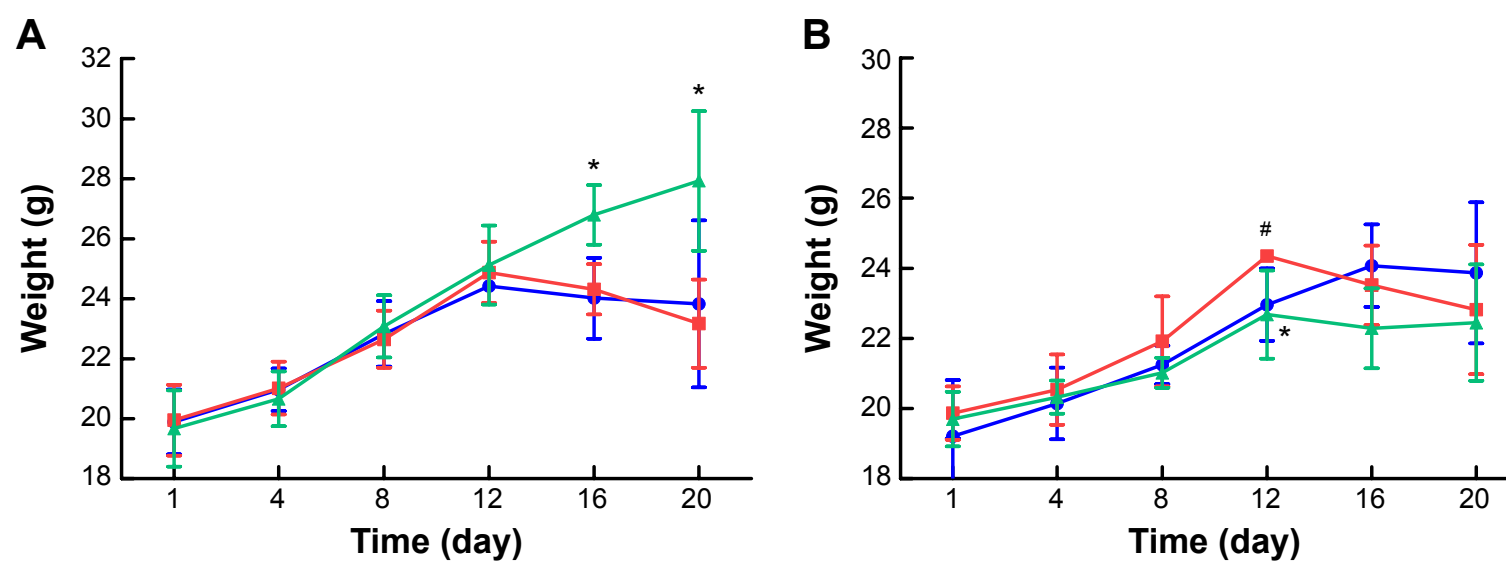

$\rightarrow$ Vehicle group $\rightarrow-$ Estrogen group $\rightarrow$ Estrogen plus tamoxifen group

Figure I The average weight in each group of mice.

Notes: Mice were weighed every 4 days after tumor cell injection. (A) The weights of male mice in various groups. (B) The weights of female mice in different groups. $* P<0.05$ versus the estrogen group; ${ }^{*} P<0.05$ versus the vehicle group; $\mathrm{n}=6$.

significantly higher than that in the vehicle group, the average weight of mice in the estrogen plus tamoxifen group was significantly decreased compared with that in the estrogen group on the twelfth day (Figure 1B).

\section{Mice-transplanted tumor weight and the tumor inhibition rate}

In female mice, the average tumor weight in the estrogen group was significantly upregulated than that in the vehicle group. Compared with the estrogen group, the average tumor weight in the estrogen plus tamoxifen group was dramatically decreased (Figure 2A). The tumor inhibition rate $=(1-$ the average tumor weight of therapy group/the average tumor weight of model group) $\times 100 \%$. The tumor inhibition rate for two estrogen groups was all negative (Figure 2B).

\section{H\&E staining in mice H\&E staining of tumor tissues}

Compared with male mice, the atypia of female mice tumor cell was more obvious, and tumor hemorrhage could be observed. In the estrogen plus tamoxifen group, tumor tissues of female mice showed a large amount of nuclear pyknosis and karyorrhexis. The tumor tissues in female mice exerted more larger necrosis area compared with those of male mice. Compared with the vehicle group, the tumor cells in the estrogen group were arranged closely, cell atypia increased,
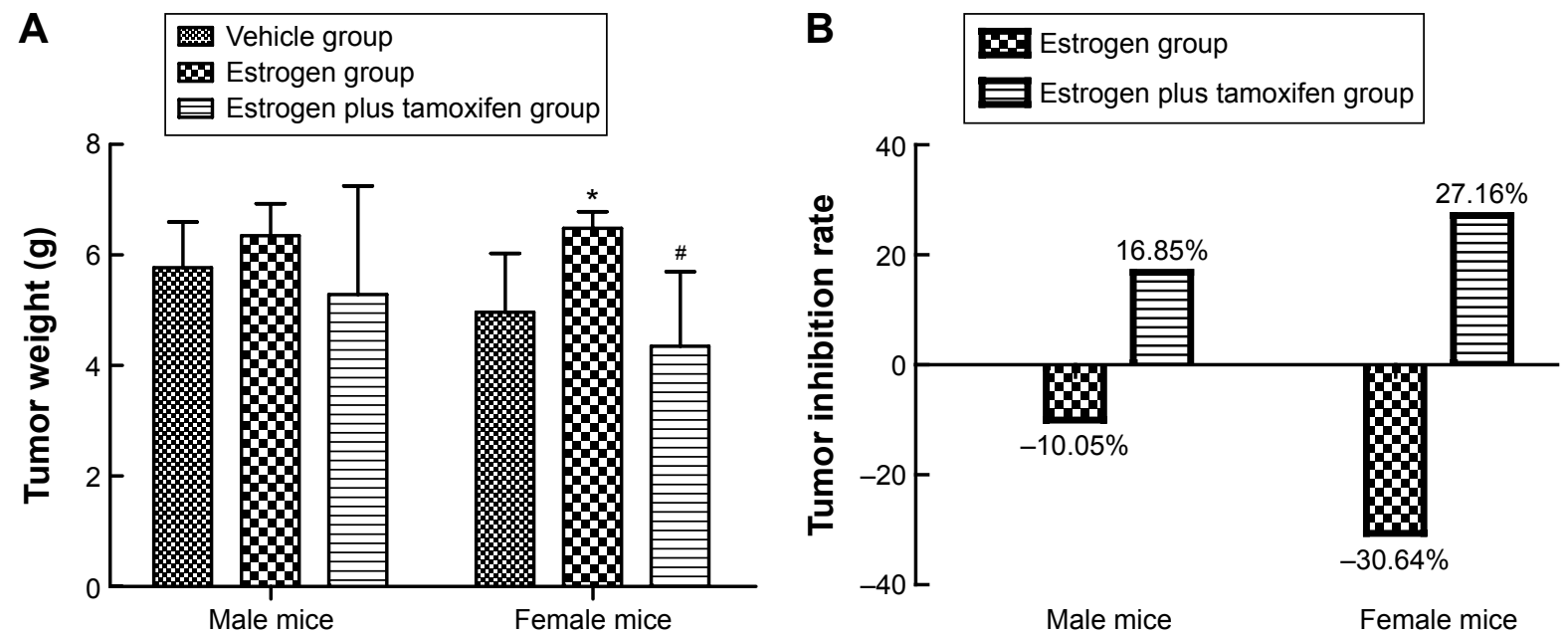

Figure 2 Tumor tissue weight and tumor inhibition rate.

Notes: $(\mathbf{A})$ The average tumor tissue weight in different groups. (B) The tumor inhibition rate in various groups. $* P<0.05$ versus the estrogen group and $\# \mathbb{P}<0.05$ versus the vehicle group. 

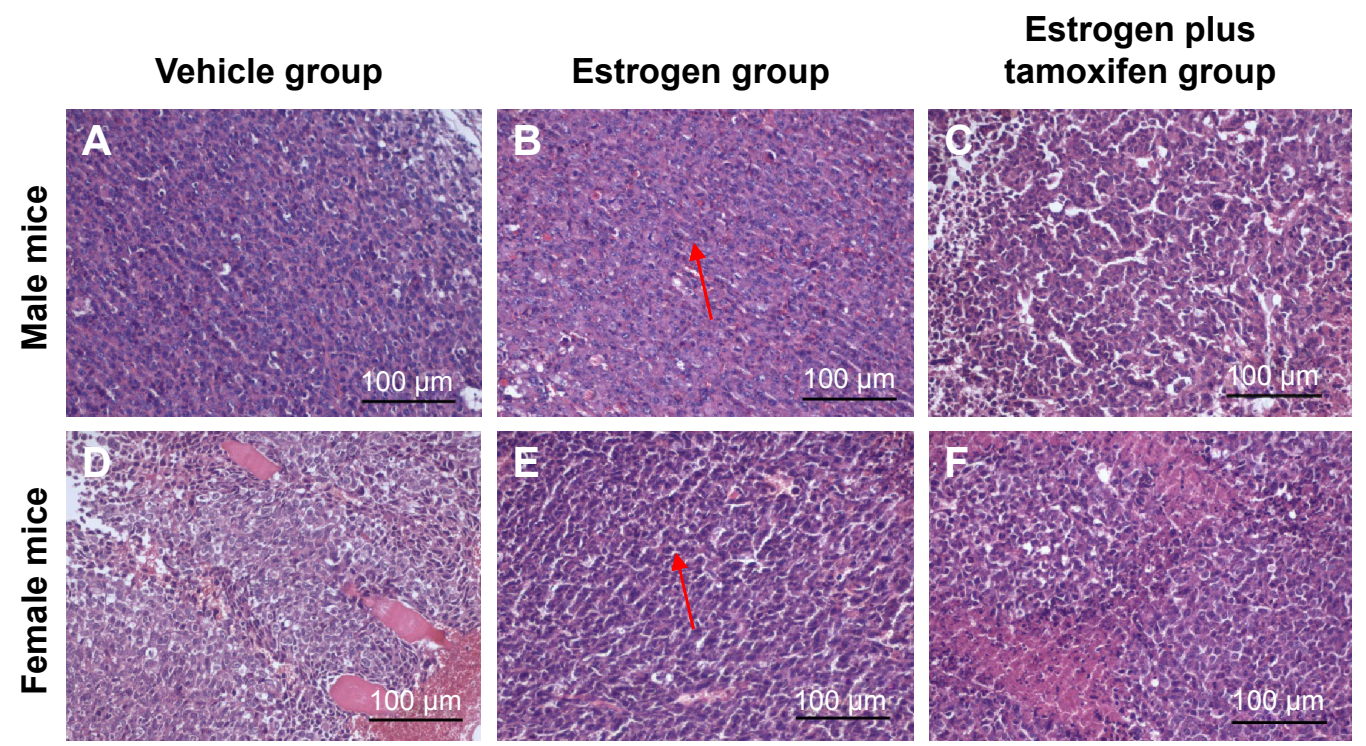

Figure 3 The images of H\&E staining for tumor tissue; $400 \times$ magnification.

Notes: (A-C) Representative male mice staining of tumor tissue from each groups. (D-F) Representative female mice staining of tumor tissue from each groups, arrows indicate nodular metastases.

Abbreviation: H\&E, hematoxylin and eosin.

pathological nuclear fission increased, necrosis area of tumor tissue was small, and microvascular in tumor tissue increased. Compared with the estrogen group, the tumor cells in the estrogen plus tamoxifen group were sparse, atypical cells decreased, pathological mitosis was reduced, nuclear pyknosis and karyorrhexis were visible, tumor tissue contains smaller patchy necrosis area, and the number of tumor tissues and surrounding microvessels decreased (Figure 3).

H\&E staining of lung tissue

Nodular metastases were mainly spread over the lung periphery, around the small blood vessels or bronchial. The vehicle group showed metastatic tumor nodules, the estrogen group showed multiple giant metastatic tumor nodules, and the estrogen plus tamoxifen group showed multiple small metastatic tumor nodules (Figure 4).

\section{The mRNA expression of ER $\alpha, E R \beta$, PI3K,AKT, E-cadherin, and vimentin in mice-transplanted tumor tissue and lung tissue The mRNA expression of ER $\alpha$}

Only in tumor tissues of male mice, the ER $\alpha$ mRNA expression had a significance: it was significantly higher in the estrogen group than in the vehicle group and was significantly lower in the estrogen plus tamoxifen group than in the estrogen group (Figure 5A).

\section{The mRNA expression of ER $\beta$}

Only in female mice, the ER $\beta$ mRNA expression had a significance: in tumor tissues and lung tissues, it was significantly higher in the estrogen group than in the vehicle group and was significantly lower in the estrogen plus tamoxifen group than in the estrogen group (Figure 5B).

\section{The mRNA expression of PI3K}

The PI3K mRNA expressions of tumor tissues and lung tissues in the estrogen group were significantly higher than that in the vehicle group, and the PI3K mRNA expressions of tumor tissues and lung tissues in the estrogen plus tamoxifen group were significantly lower than that in the estrogen group (Figure 5C).

\section{The mRNA expression of AKT}

In female mice, the AKT mRNA expression was significantly higher in the estrogen group than in the vehicle group. For both male mice and female mice, the AKT mRNA expressions in tumor tissues and lung tissues were significantly lower in the estrogen plus tamoxifen group than in the estrogen group (Figure 5D).

\section{The mRNA expression of E-cadherin}

In both male mice and female mice, the E-cadherin mRNA expression of tumor tissues was significantly upregulated in the estrogen group than in the vehicle group and was 


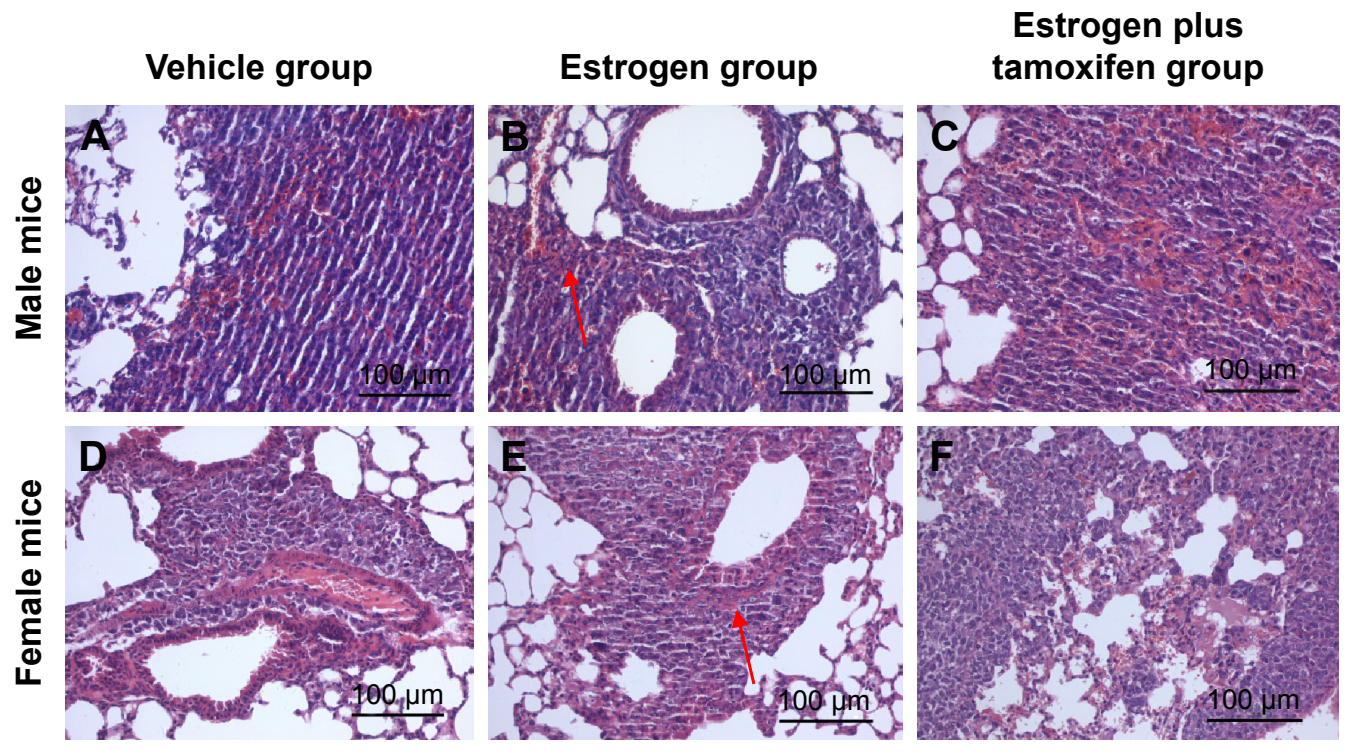

Figure 4 The images of H\&E staining for lung tissue; 400x magnification.

Notes: (A-C) Representative male mice staining from lung tissue of each groups. (D-F) Representative female mice staining of lung tissue from each groups. Arrows indicate nodular metastases.

Abbreviation: H\&E, hematoxylin and eosin.

significantly lower in the estrogen plus tamoxifen group than in the estrogen group (Figure 5E).

\section{The mRNA expression of vimentin}

There is no significant difference among various groups (Figure 5F).

\section{Protein immunohistochemical results of $E R \alpha, E R \beta, P I 3 K, A K T$, E-cadherin, and vimentin in mice- transplanted tumor tissue and lung tissue}

Protein immunohistochemical results of $E R \alpha$

ER $\alpha$, indicated by yellow color, was mainly expressed in cytoplasma and also in nuclei. Compared with the estrogen group, ER $\alpha$ was significantly lower in the estrogen plus tamoxifen group (Figure 6).

\section{Protein immunohistochemical results of $E R \beta$}

ER $\beta$ was mainly expressed in both nucleus and cytoplasma. In female mice, the estrogen group had a large amount of ER $\beta$ protein expression compared with that in the vehicle group, and tamoxifen treatment significantly reduced ER $\beta$ protein expression compared with that in the estrogen group (Figure 7).

\section{Protein immunohistochemical results of PI3K}

PI3K, indicated by yellow color, was mainly expressed in membrane or cytoplasm. All mice in the estrogen group had a large amount of PI3K protein expression compared with that in the vehicle group, and tamoxifen treatment significantly reduced PI3K protein expression compared with that in the estrogen group (Figure 8).

\section{Protein immunohistochemical results of AKT}

AKT was mainly expressed in the cytoplasm. All mice in the estrogen group had a large amount of AKT protein expression compared with that in the vehicle group. AKT protein expression was significantly lower in the estrogen plus tamoxifen group compared with that in the estrogen group (Figure 9).

\section{Protein immunohistochemical results of E-cadherin}

E-cadherin, indicated by yellow color, was mainly expressed in the cell membrane. The E-cadherin protein expression was significantly lower in the estrogen group compared with that in the vehicle group and was significantly higher in the estrogen plus tamoxifen group compared with that in the estrogen group (Figure 10). 
A

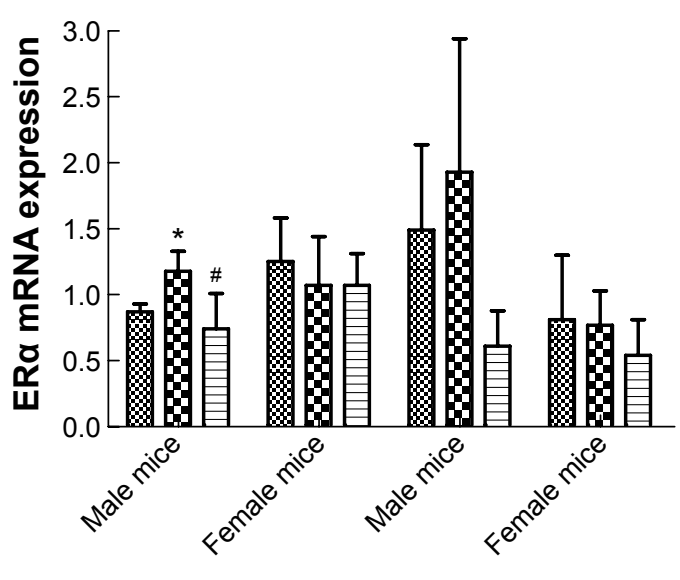

Tumor tissue Lung tissue

C

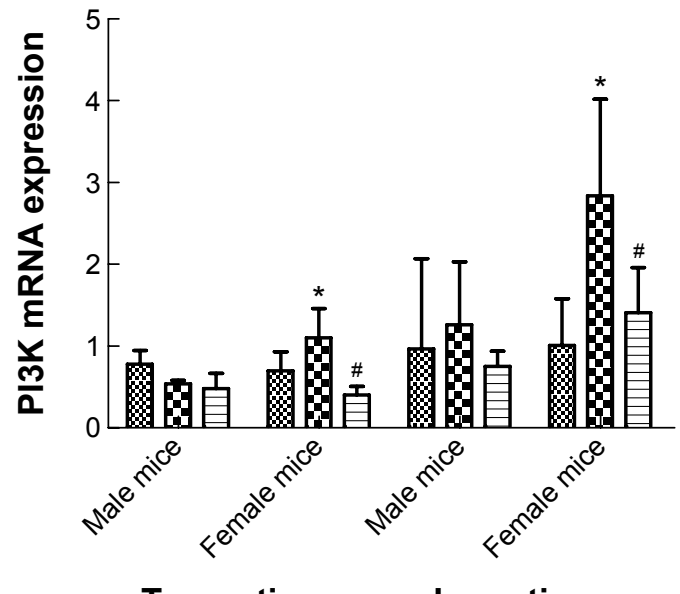

Tumor tissue Lung tissue

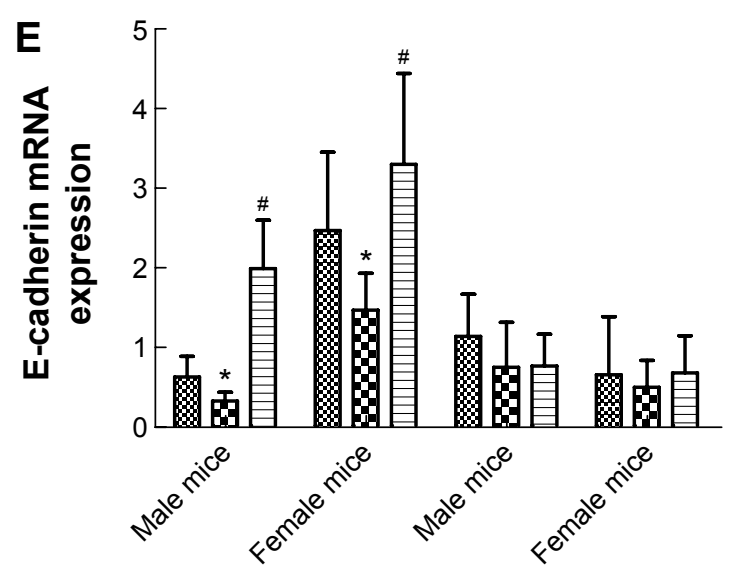

Tumor tissue Lung tissue
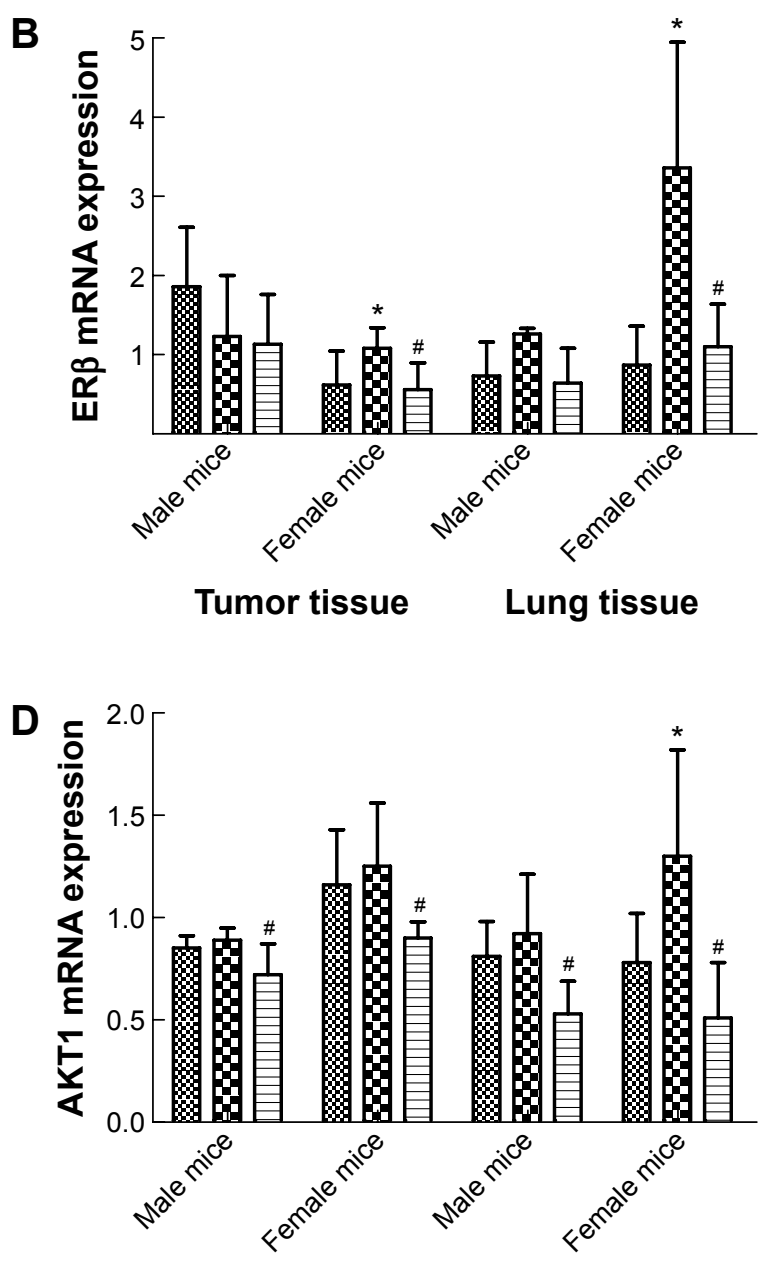

Tumor tissue Lung tissue

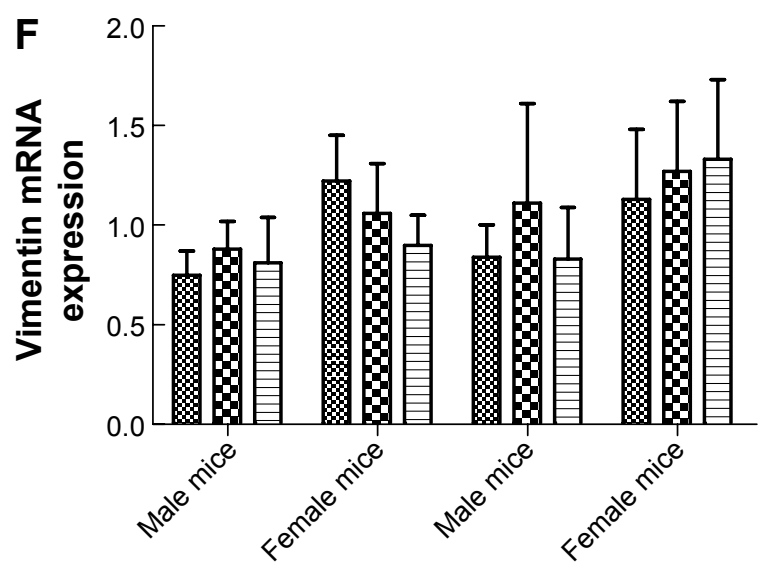

Tumor tissue

Vehicle group Estrogen group $\boxminus$ Estrogen plus tamoxifen group

Figure 5 The mRNA expression of ER $\alpha$, ER $\beta, P I 3 K, A K T$, E-cadherin, and vimentin in mice-transplanted tumor tissue and lung tissue.

Notes: (A) The mRNA expression of ER $\alpha$ in mice tumor tissue and lung tissue. (B) The mRNA expression of ER $\beta$ in mice tumor tissue and lung tissue. (C) The mRNA expression of PI3K in mice tumor tissue and lung tissue. (D) The mRNA expression of AKT in mice tumor tissue and lung tissue. (E) The mRNA expression of E-cadherin in mice tumor tissue and lung tissue. (F) The mRNA expression of vimentin in mice tumor tissue and lung tissue. ${ }^{*} P<0.05$ versus the estrogen group; ${ }^{\sharp} P<0.05$ versus the vehicle group; $\mathrm{N}=6$.

Abbreviations: $\mathrm{ER} \alpha$, estrogen receptor $\alpha$; $\mathrm{ER} \beta$, estrogen receptor $\beta$; mRNA, messenger RNA; PI3K, phosphatidylinositol 3'-kinase. 

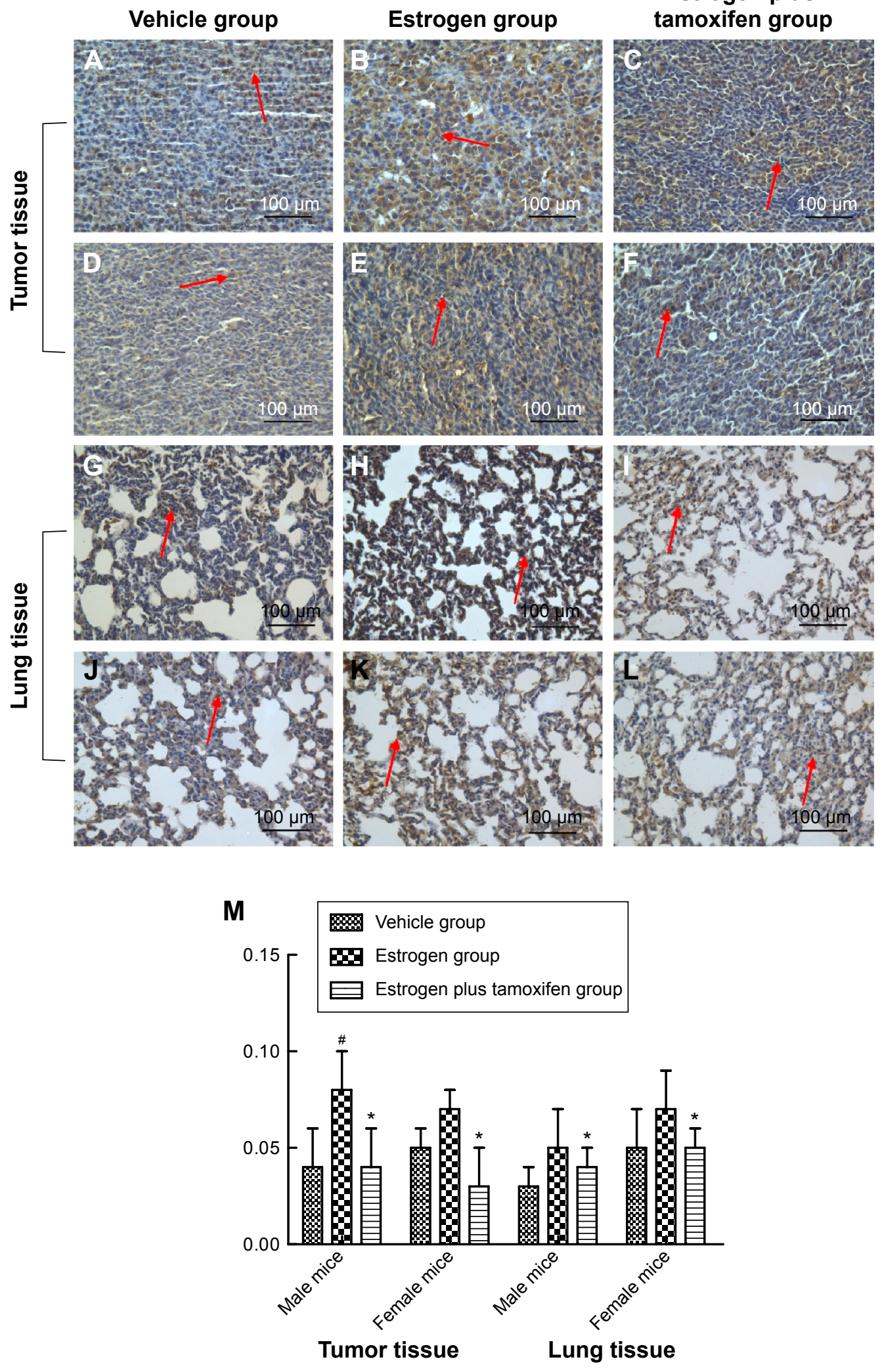

Figure 6 Protein immunohistochemical results of $E R \alpha$ in mice tumor tissue and lung tissue; 400× magnification.

Notes: (A-C) Protein immunohistochemical results of ER $\alpha$ in tumor tissues in male mice. (D-F) Protein immunohistochemical results of ER $\alpha$ in tumor tissues in female mice. (G-I) Protein immunohistochemical results of ER $\alpha$ in lung tissues in male mice. (J-L) Protein immunohistochemical results of ER $\alpha$ in lung tissues in female mice. Arrows indicate yellow or brown granules. (M) The average protein optical density of $E R \alpha$ in mice tumor tissue and lung tissue. ${ }^{* P}<0.05$ versus the estrogen group; ${ }^{\#} P<0.0$ I versus the vehicle group; $\mathrm{N}=6$.

Abbreviation: $\mathrm{ER} \alpha$, estrogen receptor $\alpha$. 

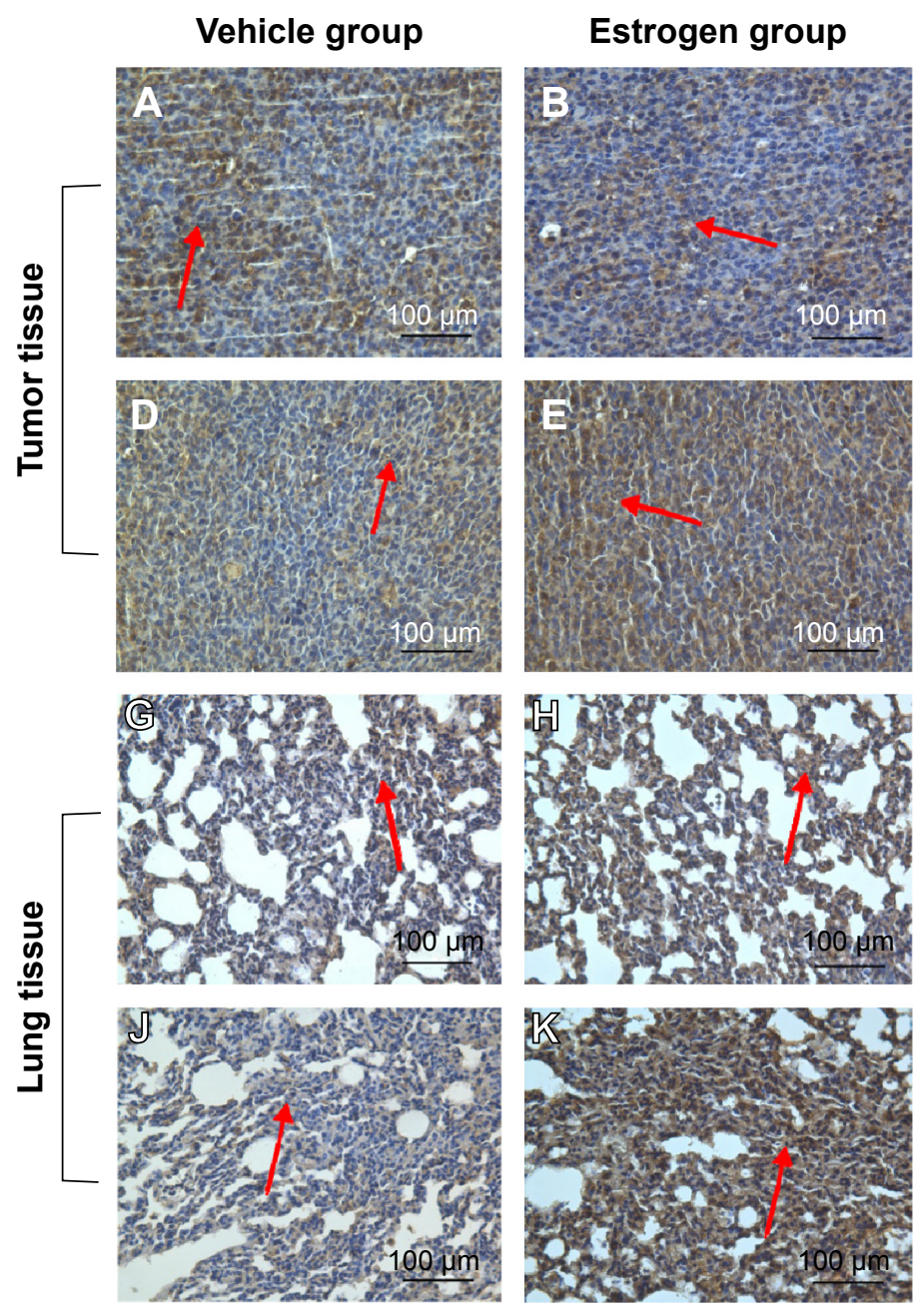

\section{Estrogen plus tamoxifen group}
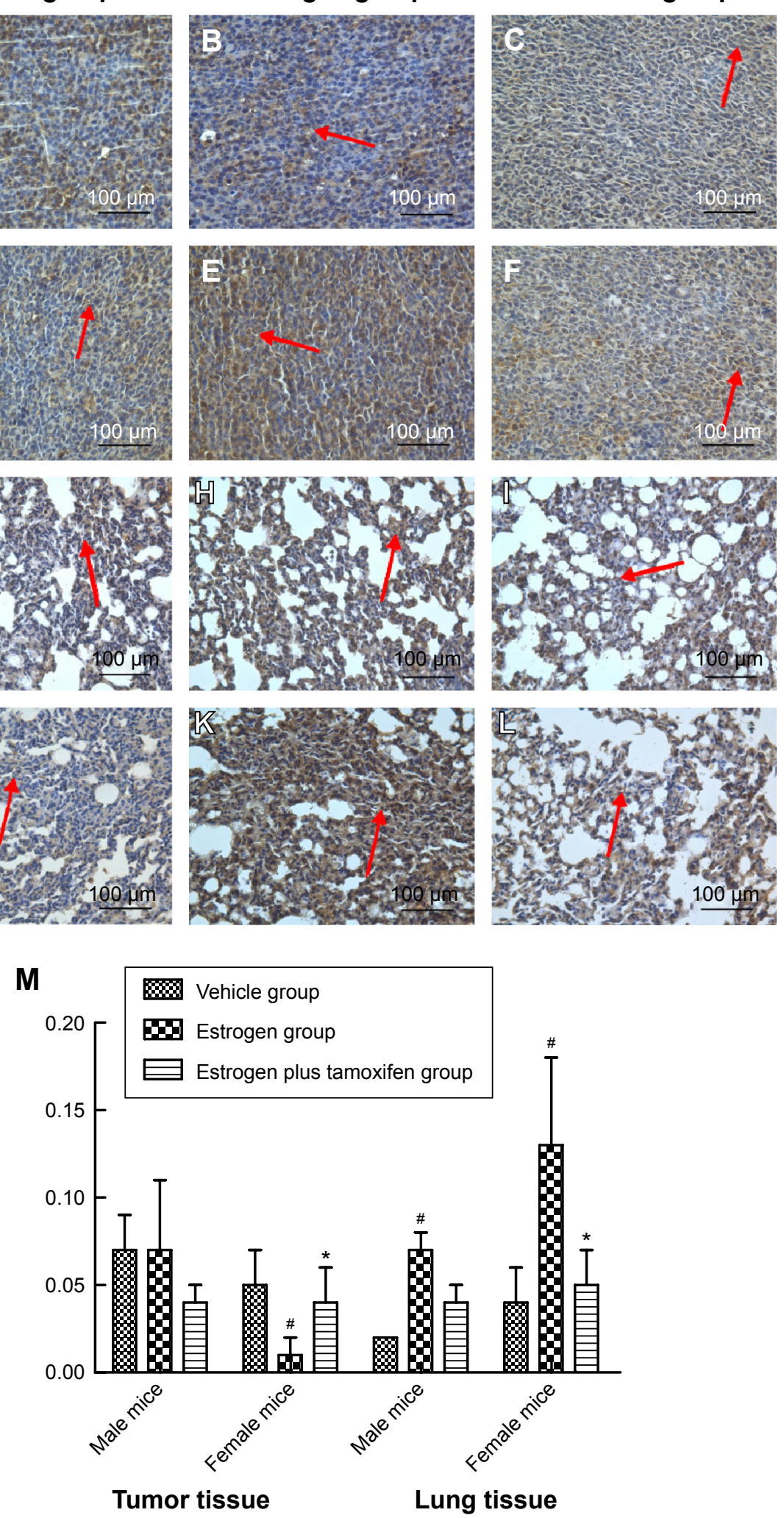

Figure 7 Protein immunohistochemical results of ER $\beta$ in mice tumor tissue and lung tissue; $400 \times$ magnification.

Notes: (A-C) Protein immunohistochemical results of ER $\beta$ in tumor tissues in male mice. (D-F) Protein immunohistochemical results of ER $\beta$ in tumor tissues in female mice. (G-I) Protein immunohistochemical results of ER $\beta$ in lung tissues in male mice. (J-L) Protein immunohistochemical results of ER $\beta$ in lung tissues in female mice. Arrows indicate yellow or brown granules. $(\mathbf{M})$ The average protein optical density of $E R \beta$ in mice tumor tissue and lung tissue. $* P<0.05$ versus the estrogen group; ${ }^{\#} P<0.01$ versus the vehicle group; $N=6$. Abbreviation: $E R \beta$, estrogen receptor $\beta$. 


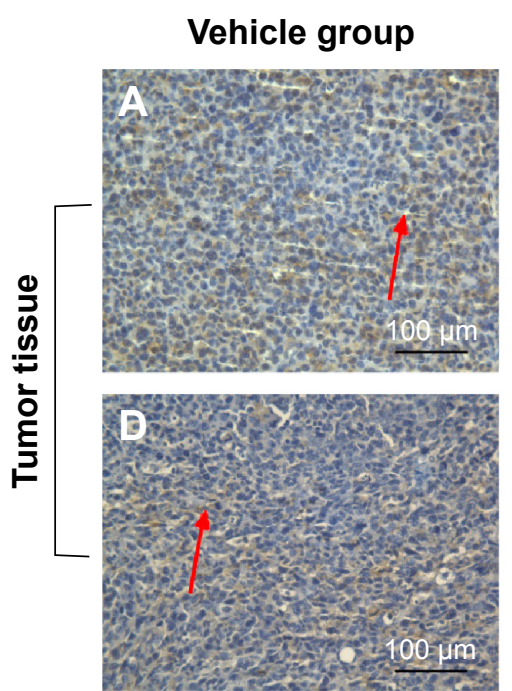

\section{Estrogen group}
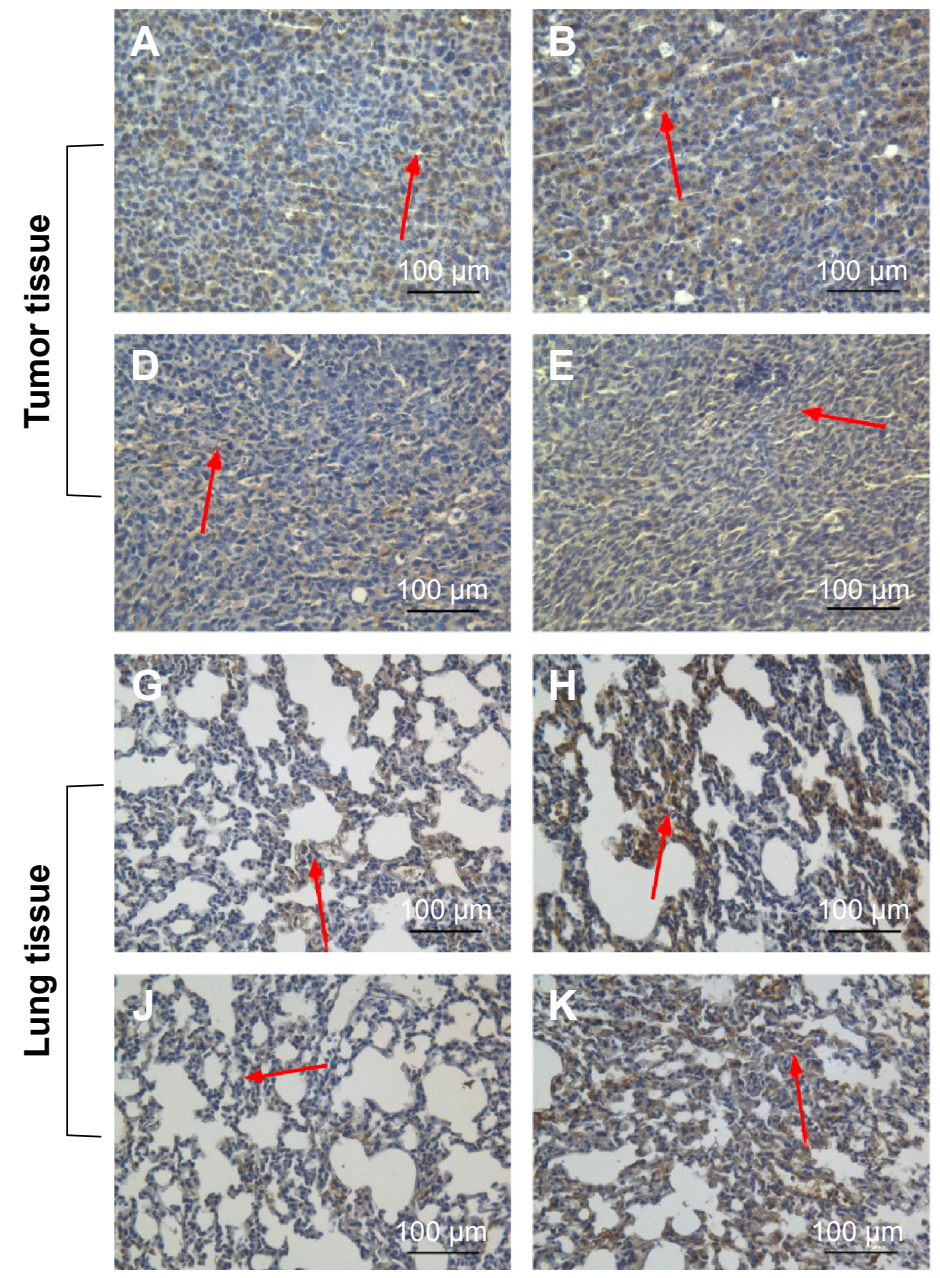

\section{Estrogen plus tamoxifen group}
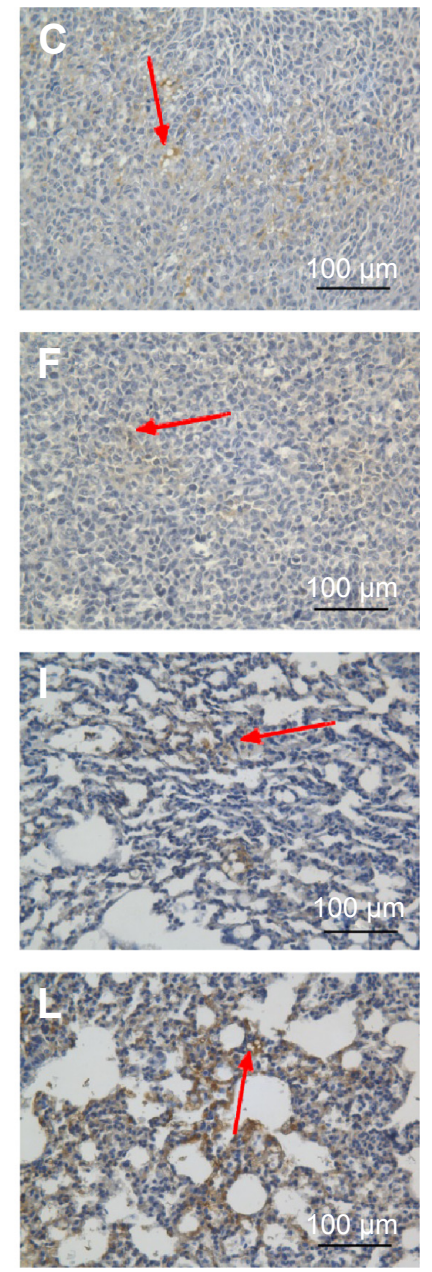

M

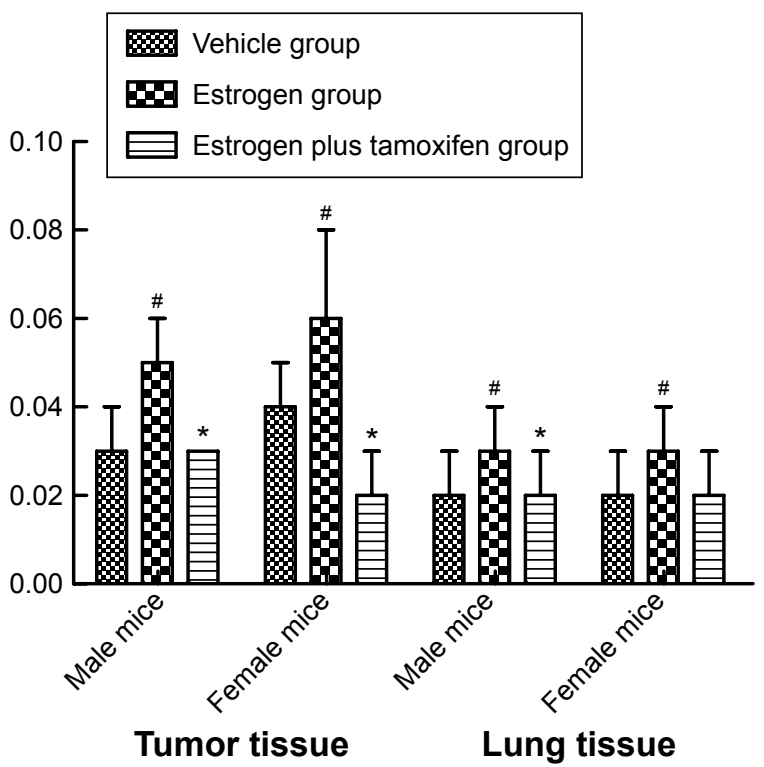

Figure 8 Protein immunohistochemical results of PI3K in mice tumor tissue and lung tissue; 400× magnification.

Notes: (A-C) Protein immunohistochemical results of PI3K in tumor tissues in male mice. (D-F) Protein immunohistochemical results of PI3K in tumor tissues in female mice. (G-I) Protein immunohistochemical results of PI3K in lung tissues in male mice. (J-L) Protein immunohistochemical results of PI3K in lung tissues in female mice. Arrows indicate yellow or brown granules. (M) The average protein optical density of $P I 3 K$ in mice tumor tissue and lung tissue. $* P<0.05$ versus the estrogen group; ${ }^{\sharp} P<0.05$ versus the vehicle group; $\mathrm{N}=6$.

Abbreviation: PI3K, phosphatidylinositol 3'-kinase. 

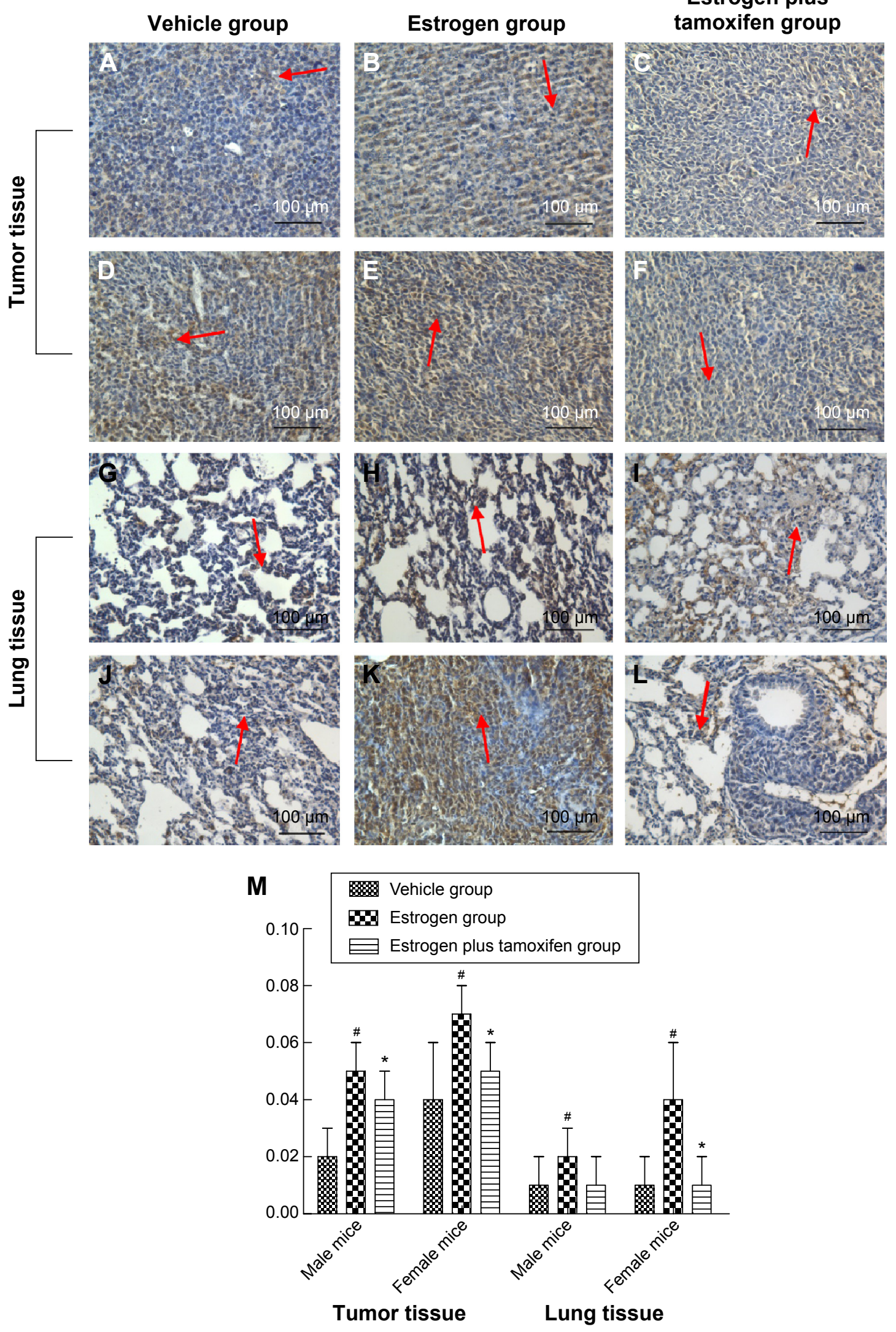

Figure 9 Protein immunohistochemical results of AKT in mice tumor tissue and lung tissue; $400 \times$ magnification.

Notes: (A-C) Protein immunohistochemical results of AKT in tumor tissues in male mice. (D-F) Protein immunohistochemical results of AKT in tumor tissues in female mice. (G-I) Protein immunohistochemical results of AKT in lung tissues in male mice. (J-L) Protein immunohistochemical results of AKT in lung tissues in female mice. Arrows indicate yellow or brown granules. (M) The average protein optical density of AKT in mice tumor tissue and lung tissue. $* P<0.05$ versus the estrogen group; $\# P<0.05$ versus the vehicle group; $\mathrm{N}=6$. 

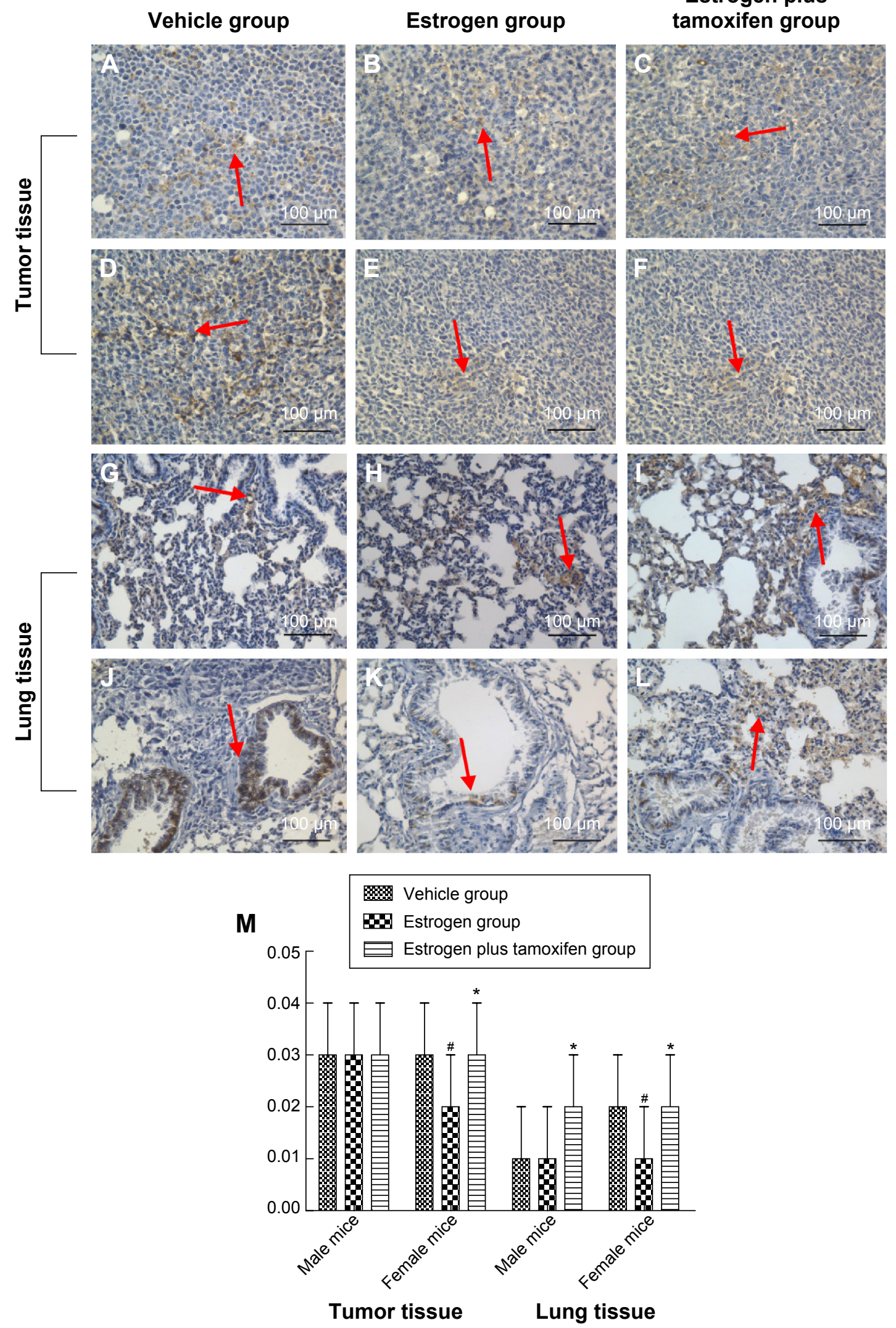

Figure 10 Protein immunohistochemical results of E-cadherin in mice tumor tissue and lung tissue; 400× magnification.

Notes: (A-C) Protein immunohistochemical results of E-cadherin in tumor tissues in male mice. (D-F) Protein immunohistochemical results of E-cadherin in tumor tissues in female mice. (G-I) Protein immunohistochemical results of E-cadherin in lung tissues in male mice. (J-L) Protein immunohistochemical results of E-cadherin in lung tissues in female mice. Arrows indicate yellow or brown granules. (M) The average protein optical density of E-cadherin in mice tumor tissue and lung tissue. $* P<0.05$ versus the estrogen group; ${ }^{P} P<0.05$ versus the vehicle group; $N=6$. 


\section{Protein immunohistochemical results of vimentin}

Vimentin, indicated by yellow or brown color, was mainly expressed in the cytoplasm. All mice in the estrogen group had the vimentin protein expression significantly increased compared with that in the vehicle group. The vimentin protein expression was significantly lower in the estrogen plus tamoxifen group compared with that in the estrogen group (Figure 11).

\section{Discussion}

The formation and development of lung cancer are extremely complicated processes, a number of studies have demonstrated that estrogen and ER played an important role in the development of lung cancer, including induction of multiple proto-oncogene activation, cell proliferation, and promoting tumor metastasis. ${ }^{10-12}$ However, the underlying mechanism is not clear till now. In the present study, we revealed that the estrogen regulated lung cancer by ER-EMT signaling pathway for the first time. Male and female mice were studied separately to detect, mice of the same sex were compared between groups, the effects of estrogen on different sexes. Although estrogen is higher in female mice than in male mice, estrogen is necessary to maintain the normal physiological function of female mice. Hence, it will not affect the results of the experiment.

We chose heterotopic lung cancer models as our cancer model based on the fact that heterotopic lung cancer models have become well accepted recently, and more and more research papers investigating lung cancer have been published using this model. ${ }^{13-16}$ This method of modeling has a high rate of tumor formation, and it is easy to track and monitor tumor growth. Although it has limitations, the host microenvironment of tumor cell growth is different from that of the primary tumor, which may affect the expression of some characteristics of the tumor, and heterotopic lung cancer models rarely produce transplantation outside of the implant. In addition to numerous mechanisms for metastasis to other organs, more work needs to be done in our future investigation.

The expression of two subtypes of ER in lung cancer, $E R \alpha$ and ER $\beta$, has always been controversial. Kawai et al analyzed the expression of ER in 132 cases of NSCLC tissues and discovered that ER $\alpha$ and $E R \beta$ were widely expressed in the NSCLC. ${ }^{17}$ Nose et al also found high levels of ER $\alpha$ and ER $\beta$ expressions in lung adenocarcinoma. ${ }^{18}$ While other researchers argue that the expression of ER $\beta$ in lung cancer was significantly higher than that of ER $\alpha$. Dougherty et al found $E R \alpha$ and $E R \beta$ expressions in all lung adenocarcinoma cell lines, ${ }^{19}$ and ER $\beta$ expression was higher than that of ER $\beta$. Niikawa et al found that the expression percentage of ER $\alpha$ and ER $\beta$ was $54 \%$ and $90 \%$, respectively. ${ }^{1}$ Abe et al discovered that the percentage of ER $\alpha$ and ER $\beta$ was $0.95 \%$, and $71.43 \%$, respectively. ${ }^{20}$ In our study, we found that ER $\alpha$ mRNA was only expressed in tumor tissues of male mice, ER $\beta$ mRNA was expressed in tumor tissues and lung tissues of female mice, and ER $\beta$ protein was expressed in lung tissues of male mice. Our finding was consistent with the results of ER $\beta$ in lung cancer and was significantly higher than that of ER $\alpha$. However, our study has a shortage that we have not verified the ERs involvement by determining the expression of ER target genes such as c-Myc. We will add these target genes in the next research.

The main features of EMT include decreased epithelial cell markers (E-cadherin, CK19 protein) and increased mesenchymal cell markers ( $\mathrm{N}$-cadherin, vimentin). This phenotypic changes lead to alerted biological behavior and reduced adhesion capacity of tumor cells, eventually causing tumor cell invasion. E-cadherin is the most widely expressed proteins. E-cadherin mediates the cell-cell adhesion, which plays an important role in regulating cell behavior. Loss of E-cadherin function can initiate EMT, which induced the differentiation and invasion of tumor. ${ }^{21-23}$ Vimentin is an important cytoskeletal protein, mainly distributed in leaf tissue and cells. Recently, vimentin was also found in malignant tumor, suggesting the potential regulatory roles of vimentin on malignant tumor. Hence, we selected detecting the expression of vimentin and E-cadherin in the lung tissues and tumor tissues, to understand the occurrence and development of EMT in lung cancer. In our present study, reduced expression of E-cadherin mRNA in tumor tissues of the estrogen group was observed in both male mice and female mice, while in the estrogen plus tamoxifen group, the expression of E-cadherin mRNA increased compared with the estrogen group. The expression of vimentin increased in all estrogen groups, while tamoxifen treatment significantly repressed vimention expression compared with the estrogen group.

Based on our quantified results, we demonstrated that estrogen could promote tumor growth and activate the PI3K/AKT signaling pathway, which was consistent with previous findings..$^{3-5} \mathrm{We}$ also showed that estrogen could subsequently induce the regulation of epithelial mesenchymal cell transformation to promote tumor metastasis. However, this effect was not obvious in male mice. Tamoxifen, through inhibiting the effects of estrogen, prevented the lung 

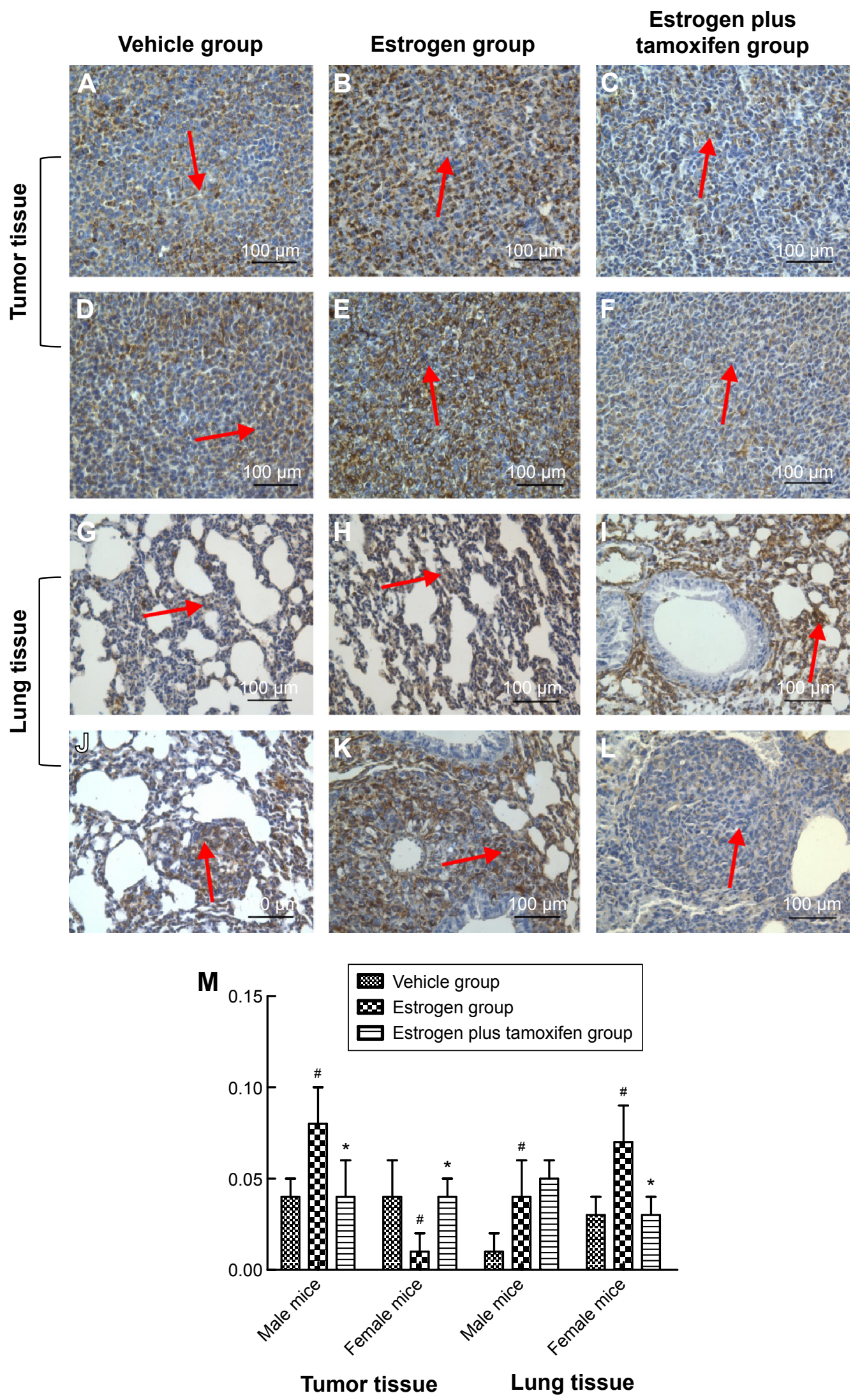

Figure I I Protein immunohistochemical results of vimentin in mice tumor tissue and lung tissue; 400× magnification.

Notes: (A-C) Protein immunohistochemical results of vimentin in tumor tissues in male mice. (D-F) Protein immunohistochemical results of E-cadherin in tumor tissues in female mice. (G-I) Protein immunohistochemical results of vimentin in lung tissues in male mice. (J-L) Protein immunohistochemical results of vimentin in lung tissues in female mice. Arrows indicate yellow or brown granules. (M) The average protein optical density of vimentin in mice tumor tissue and lung tissue. $* P<0.05$ versus the estrogen group; ${ }^{P}<0.05$ versus the vehicle group; $\mathrm{N}=6$. 
epithelial-mesenchymal cells transformation both in tumor tissues and lung tissues and suppressed tumor metastasis. Yet, this effect was not obvious in male mice.

There is a limited breakthrough of lung cancer therapeutic strategies nowadays; thus, endocrine therapy for lung cancer draws more and more attention. Our present study also found that PI3K/AKT and EMT signaling pathways served as the downstream signaling pathway of estrogen, suggesting endocrine therapy as a promising strategy for lung cancer. In our future study, we could carry out a large-scale, multicenter, randomized, double-blind clinical experiment to verify the effects of endocrine therapy on lung cancer. Inspiring results from our animal experiments suggest that endocrine therapy may improve the efficiency of lung cancer treatment.

\section{Acknowledgment}

The authors would like to thank Dr Wenlong Ren (Pharmaceutical Engineering Research Center, Shanghai, People's Republic of China) for the help and human lung adenocarcinoma cell line.

\section{Disclosure}

The authors report no conflicts of interest in this work.

\section{References}

1. Niikawa H, Suzuki T, Miki Y, et al. Intratumoral estrogens and estrogen receptors in human non-small cell lung carcinoma. Clin Cancer Res. 2008; 14(14):4417-4426.

2. Chaudhuri K, Thomas A, Walker MJ, et al. Steroid receptors in human lung cancer cytosols. Cancer Lett. 1982;16(3):327-332.

3. Pietras RJ, Márquez DC, Chen HW, Tsai E, Weinberg O, Fishbein M. Estrogen and growth factor receptor interactions in human breast and non-small cell lung cancer cells. Steroids. 2005;70(5):372-381.

4. Stabile LP, Lyker JS, Gubish CT, Zhang W, Grandis JR, Siegfried JM. Combined targeting of the estrogen receptor and the epidermal growth factor receptor in non-small cell lung cancer shows enhanced antiproliferative effects. Cancer Res. 2005;65(4):1459-1470.

5. Zhang G, Liu X, Farkas AM, et al. Estrogen receptor $\beta$ functions through nongenomic mechanisms in lung cancer cells. Mol Endocrinol. 2009; 23(2):146-156.

6. Nakashima H, Hashimoto N, Aoyama D, et al. Involvement of the transcription factor twist in phenotype alteration through epithelialmesenchymal transition in lung cancer cells. Mol Carcinog. 2012;51(5): 400-410.
7. Boyer B, Vallés AM, Edme N. Induction and regulation of epithelialmesenchymal transitions. Biochem Pharmacol. 2000;60(8): 1091-1099.

8. Savagner P. Leaving the neighborhood: molecular mechanisms involved during epithelial - mesenchymal transition. Bioessays. 2001;23(10): 912-923.

9. Grille SJ, Bellacosa A, Upson J, et al. The protein kinase Akt induces epithelial mesenchymal transition and promotes enhanced motility and invasiveness of squamous cell carcinoma lines. Cancer Res. 2003;63(9): 2172-2178

10. Beattie CW, Hansen NW, Thomas PA. Steroid receptors in human lung cancer. Cancer Res. 1985;45(9):4206-4214.

11. Chaudhuri PK, Thomas PA, Walker MJ, Briele HA, Das Gupta TK, Beattie CW. Steroid receptors in human lung cancer cytosols. Cancer Lett. 1982;16(3):327-332.

12. Canver CC, Memoli VA, Vanderveer PL, Dingivan CA, Mentzer RM Jr. Sex hormone receptors in non-small-cell lung cancer in human beings. J Thorac Cardiovasc Surg. 1994;108(1):153-157.

13. Matsuo Y, Park JH, Miyamoto T, et al. TOPK inhibitor induces complete tumor regression in xenograft models of human cancer through inhibition of cytokinesis. Sci Transl Med. 2014;6(259):259ra145.

14. Chen N, Ren M, Li R, et al. Bevacizumab promotes venous thromboembolism through the induction of PAI-1 in a mouse xenograft model of human lung carcinoma. Mol Cancer. 2015;14:140.

15. Qu Y, Qu B, Wang X, Wu R, Zhang X. Knockdown of NF-кB p65 subunit expression suppresses growth of nude mouse lung tumour cell xenografts by inhibition of Bcl-2 apoptotic pathway. Cell Biochem Funct. 2015;33(5):320-325.

16. Chen YQ, Chen G. Combined therapeutic effect and molecular mechanisms of metformin and cisplatin in human lung cancer xenografts in nude mice. J Cancer Res Ther. 2015;11(2):324.

17. Kawai $H$, Ishii A, Washiya $K$, et al. Estrogen receptor $\alpha$ and $\beta$ are prognostic factors in non-small cell lung cancer. Clin Cancer Res. 2005;11(14): 5084-5089.

18. Nose N, Sugio K, Oyama T, et al. Association between estrogen receptor- $\beta$ expression and epidermal growth factor receptor mutation in the postoperative prognosis of adenocarcinoma of the lung. J Clin Oncol. 2009;27(3):411-417.

19. Dougherty SM, Mazhawidza W, Bohn AR, et al. Gender difference in the activity but not expression of estrogen receptors $\alpha$ and $\beta$ in human lung adenocarcinoma cells. Endocr Relat Cancer. 2006;13(1):113-134.

20. Abe K, Miki Y, Ono K, et al. Highly concordant coexpression of aromatase and estrogen receptor $\beta$ in non-small cell lung cancer. Hum Pathol. 2010;41(2):190-198.

21. Canel M, Serrels A, Frame MC, Brunton VG. E-cadherin-integrin crosstalk in cancer invasion and metastasis. $J$ Cell Sci. 2013;126(2): 393-401.

22. Chu B, Deng C, Wang L. Expressions of N-cadherin and $\beta$-catenin in glioma and their significance. Chin J Neurosurg Dis Res. 2002;11(1): 24-27.

23. Liu YN, Liu Y, Lee HJ, Hsu YH, Chen JH. Activated androgen receptor downregulates E-cadherin gene expression and promotes tumor metastasis. Mol Cell Biol. 2008;28(23):7096-7108.
OncoTargets and Therapy

\section{Publish your work in this journal}

OncoTargets and Therapy is an international, peer-reviewed, open access journal focusing on the pathological basis of all cancers, potential targets for therapy and treatment protocols employed to improve the management of cancer patients. The journal also focuses on the impact of management programs and new therapeutic agents and protocols on

\section{Dovepress}

patient perspectives such as quality of life, adherence and satisfaction. The manuscript management system is completely online and includes a very quick and fair peer-review system, which is all easy to use. Visit http://www.dovepress.com/testimonials.php to read real quotes from published authors. 